Published in final edited form as:

IEEE Trans UItrason Ferroelectr Freq Control. 2013 January ; 60(1): . doi:10.1109/TUFFC.2013.2538.

\title{
Nanoparticle Delivery Enhancement With Acoustically Activated Microbubbles
}

\author{
Lee B Mullin ${ }^{1}$, Linsey C Phillips ${ }^{1}$, and Paul A Dayton ${ }^{1,2}$ \\ 1Joint Department of Biomedical Engineering The University of North Carolina at Chapel Hill, and \\ North Carolina State University
}

\section{Abstract}

The application of microbubbles and ultrasound to deliver nanoparticle carriers for drug and gene delivery is an area that has expanded greatly in recent years. Under ultrasound exposure, microbubbles can enhance nanoparticle delivery by increasing cellular and vascular permeability. In this review, the underlying mechanisms of enhanced nanoparticle delivery with ultrasound and microbubbles and various proposed delivery techniques are discussed. Additionally, types of nanoparticles currently being investigated in preclinical studies, as well as the general limitations and benefits of a microbubble-based approach to nanoparticle delivery are reviewed.

\section{Keywords}

Ultrasound; Microbubble; Contrast Agent; Nanoparticle; Delivery

\section{Introduction}

The use of ultrasound microbubble contrast agents has expanded beyond their primary role in diagnostics and into the research fields of drug and gene therapy [1-4]. Originally approved for use in echocardiography, microbubble contrast agents are encapsulated gaseous microspheres that improve the quality of ultrasound images due to the difference in acoustic impedance between their gaseous core and the surrounding medium and due to their nonlinear oscillation in an acoustic field [1-5]. The shells of the microbubbles are composed of materials such as proteins, polymers, or lipids, while the gas core is typically a high molecular weight gas such as a perfluorocarbon or sulfur hexafluoride [6]. Microbubbles have been utilized for imaging myocardial perfusion $[7,8]$, left ventricular opacification $[9$, 10], blood-perfusion in tumors [11, 12], liver [13], and kidney [14], and for molecular targeting of angiogenesis $[15,16]$ or inflammation $[17,18]$.

Ultrasound is widely used in the clinic because it is safe, inexpensive, and portable. Additionally, ultrasound has the ability to focus deep within tissue, which can be taken advantage of for therapeutic applications. Ultrasound, without the aid of microbubbles, is well established to have therapeutic uses in the areas of hyperthermia [19, 20], tissue ablation [21, 22], lithotripsy [23, 24], and thrombolysis [25-27]. When microbubbles are combined with ultrasound for therapy, the applications extend into fields of drug and gene delivery [27-32], and particularly chemotherapy [1,33].

The development of a drug or gene delivery method that could target a tumor or organ with high specificity and improve therapeutic efficacy, while reducing side effects, is of

\footnotetext{
${ }^{2}$ Author to whom correspondence should be addressed Paul A. Dayton Campus Box 7575, UNC Chapel Hill Chapel Hill, NC 27599 padayton@bme.unc.edu.
} 
particular interest to many areas of medicine [34,35]. The combination of ultrasound technology and nanoparticle drug capabilities has developed into a promising method of achieving targeted drug delivery. In this review, we discuss the underlying mechanisms of nanoparticle delivery with ultrasound and microbubbles, and assess various proposed delivery techniques. Additionally, we examine the types of nanoparticles currently being investigated in preclinical studies, as well as the general limitations and benefits of a microbubble-based approach to nanoparticle delivery.

\section{Nanoparticles}

The use of nanoparticles in drug and gene delivery is rapidly gaining popularity. Although strictly defined by the National Cancer Institute as any particle with at least one dimension under $100 \mathrm{~nm}$, in this review the term nanoparticle will be used to define any sub-micron vehicle, often capable of carrying a therapeutic payload. Nanoparticles vary in shape and size, along with physical and therapeutic properties. Some common types of nanoparticles are micelles, liposomes, dendrimers, solid nanoparticles, emulsions, and microemulsions, which are detailed extensively in $[34,36,37]$. Nanoparticles are often exploited as delivery vehicles by encapsulating a therapeutic compound that may otherwise cause systemic toxicity if delivered in free form. Many nanoparticle delivery vehicles show promise for carrying high therapeutic payloads, controllable release rates, and targeting abilities - both passive and active [38]. By simply altering surface properties, various aspects of the in-vivo performance can be modified [39].

In cancer therapy the small size of nanoparticles is particularly advantageous within tumor vasculature. Solid tumors incite blood vessels with larger diameters and increased permeability [40]. In many tumors, the vessels are leaky, with inter-endothelial gaps an average of 380-780 $\mathrm{nm}$, but with some as large as over $1 \mu \mathrm{m}$ depending on tumor type and location [41]. Furthermore, high pressure and low lymphatic drainage in tumors decreases the clearance of high molecular weight nanoparticles from the tumor interstitium [42]. These abnormal properties in combination form the enhanced permeability and retention (EPR) effect which permits increased retention of nanoparticles in tumors [43, 44]. Because typical nanoparticle sizes prevent extravasation from normal vasculature, they are passively targeted to tumor tissue.

\section{Nanoparticles and Ultrasound}

Although the subject is beyond the scope of this review, ultrasound alone has been shown to improve nanoparticle delivery through thermal or mechanical processes. Ultrasonic heating can cause direct effects on the tissue itself by changing blood flow and vascular pressure, or can activate an agent such as a thermally sensitive nanoparticle or nanodroplet [20, 45]. The use of ultrasound and nanoparticles has also gained interest in the field of dentistry. High intensity focused ultrasound (HIFU) has been shown to aid in delivery of antibacterial agents into dentinal tubules by inducing cavitation $[46,47]$.

In the field of therapeutic ultrasound with microbubbles, the most commonly used types of nanoparticles are quantum dots [48], liposomes [49-52], and poly(lactic-co-glycolic acid) (PLGA) nanoparticles [53, 54]. Quantum dots are often used in studies in place of nanoparticle drugs to characterize delivery vehicles and evaluate successful delivery into targeted tissue. Doxorubicin-containing liposomes have been used extensively in ultrasound and microbubble delivery studies (see Table 1). One reason for their popularity in research studies is that several forms, known as Doxil or Caelyx, DaunoXome and Myocet, are already FDA approved for use in the clinic. Doxorubicin is also inherently fluorescent, which makes optical tracking of delivery feasible. Another form of liposome used with microbubble ultrasound delivery is the lipoplex, which is a liposome containing genetic 
material such as plasmid DNA [55-57]. This method protects the DNA during in-vivo circulation and allows a higher amount of genetic material to be delivered [55, 56].

\section{Mechanisms}

Ultrasound exposure in the presence of microbubbles can increase both cellular and vascular permeability, leading to enhanced nanoparticle delivery. An increase in cell permeability ensues from the formation of pores in the cell membrane during a process called sonoporation. At higher pressures, ultrasound alone can cause the formation of pores within the cell membrane [58]. This effect is enhanced with the addition of microbubbles. Although the exact mechanisms are not fully understood, the oscillation of microbubbles in an ultrasound field creates transient pores in the lipid bilayer [59-61]. The degree of sonoporation is dependent on the cavitation behavior of the microbubbles, which is in turn dependent on the acoustic conditions applied. Both stable and inertial cavitation have been shown to result in pore formation [1,28]. During stable cavitation, the microbubble oscillates without disruption, whereas during inertial cavitation, the microbubble is unstable and fragments [1]. Streaming of fluid around the bubble can occur in both cases and causes shearing of the cellular membrane [62,63]. When microbubbles near cellular membranes are exposed to high energy pulses they often form microjets during collapse, resulting in high shear stresses from streaming and shockwaves that are thought to lead to pore formation [64, 65]. Along with creating openings in cells, the cavitation response of microbubbles may also facilitate uptake by forcing the nanoparticles into the cell through microjets [66].

Pore formation can be either transient (reversible) or permanent. Transient pore formation has been observed in-vitro wherein pores remained open for seconds to hours. In some instances, pore openings have been reported up to 24 hours after ultrasound exposure [67]. Permanent pore formation is undesirable in most applications, as it leads to cell death. Consequently, care must be taken in selecting appropriate acoustic conditions as cell death can occur with sufficiently high or long ultrasound exposure $[62,63,68]$. For example, Deng et al. observed an increased transmembrane current in cells subjected to both ultrasound and the presence of microbubbles indicating increased membrane porosity[69]. Cells recovered to resting levels in about 4 to 10 seconds following insonation for approximately one second at $1 \mathrm{MHz}$ and $1 \mathrm{MPa}$ pressure, but higher ultrasound intensities (> $1 \mathrm{MPa}$ ), resulted in irreversible cell damage and cell death. In general, reagent delivery increases with increasing acoustic pressure, but so too does the likelihood of cell apoptosis [68-72].

Many groups are also investigating cellular changes that occur as a result of ultrasound exposure, including changes in calcium levels, cell signaling pathways, and endocytosis [60, 73]. In a study on gene delivery to BLM melanoma cells, Lentacker et al. found that lipoplexes were directly entering the cell cytoplasm through sonoporation rather than endocytosis[56]. The uptake was seen to occur during or immediately after ultrasound exposure. Meijering et al. also observed small molecules ( $4.4 \mathrm{kDa}$ and $70 \mathrm{kDa})$ entering the cell membrane via pores, however they found that larger molecules (155 kDa and $400 \mathrm{kDa})$ were entering into the cell through vesicle formation in endocytosis [60]. The role of calcium in sonoporation has been investigated and is believed to aid in cell recovery after pore formation [74]. Other cellular changes that have been observed are hyperpolarization of the cell membrane, release of free radicals, and increased levels of hydrogen peroxide [74, 75]. Yang et al. recorded differences in cell viability and permeability depending on the stage of cell growth, indicating the cell cycle may play a role in cell permeability [74]. 
With respect to vessel permeability, effects can range from mild reversible permeability enhancement to gross vessel rupture, depending on the microbubble and acoustic parameters [76-80]. Results from many groups have suggested that large molecules (such as dextrans), as well as nanoparticles, enter into the interstitial space after sonication with microbubbles [81-84]. This vascular permeability is expected to be a result of the interaction between microbubbles and vessel walls. Caskey et al. studied the effects of insonated microbubbles within ex-vivo vessels and observed both asymmetric collapse and jet formation near the vessel wall [85]. Chen et al. also studied microbubbles within ex-vivo vessels and observed that jet formation occurs away from the vessel wall [86-88].

Acoustic radiation force also enhances nanoparticle delivery. Radiation force, or the Bjerknes force, refers to the directional forces experienced by objects in an ultrasound field. Due to the transfer of momentum from the sound wave to the bubble, bubbles are translated in the direction of the acoustic wave propagation [89, 90]. In order to achieve translation, radiation force pulse sequences require a high duty cycle which is low in amplitude so as to not rupture the microbubbles. Radiation force applied perpendicularly to vessel orientation can result in microbubbles being pushed to the vessel walls, where they can accumulate [91].The phenomena has been shown to aid in delivery of nanoparticles when microbubbles are used $[49,93-95]$. When nanoparticles are attached to the microbubble, local concentration of nanoparticles can be increased by pushing the microbubbles against the vessel wall in one location $[91,92,96]$.

\section{Types of administration}

There are two main administration methods employed for nanoparticle delivery with ultrasound and microbubbles: un-bound and bound nanoparticles. In the first method, the nanoparticles are not associated with the microbubbles, but are either injected separately coadministered. If separate injections are performed, the order of injection may vary as long as microbubbles are present when ultrasound is applied. Lin et al. showed no significant difference in tumor accumulation between quantum dot injected before or after insonation as long as microbubbles were present during the ultrasound [97].

The second method of delivery requires the nanoparticles to be attached to the microbubble prior to injection and ultrasound treatment. There are numerous ways to associate the nanoparticle with the microbubble. One of the most common methods to attach a nanoparticle to the microbubble is through biotin-avidin interactions. Biotinylated microbubbles are used to attach either avidin or streptavidin nanoparticles, or in some cases an avidin linker is used to link biotinylated particles [49, 52]. Although biotin-avidin linkage is suitable for proof of concept studies, it is not ideal for in-vivo use because it can induce an immunogenic response $[49,98]$. An alternative to this method is to use maleimide-thiol chemistry. Maleimide conjugation is often used in molecular imaging studies to create targeted microbubbles, and can also be applied to nanoparticle attachment to the shell of the microbubble [51]. Another covalent binding possibility is illustrated by Burke et al. where PLGA nanoparticles were coupled to albumin microbubbles through carbodiimide chemistry [53]. Oligonucleotides have also been employed as tethers to link vesicles to microbubbles through hybridization of complementary lipid-linked DNA oligonucleotides [99].

Electrostatic binding of nanoparticles to microbubbles is often implemented in gene delivery studies wherein negatively charged DNA is attached to positively charged microbubbles with shells composed of a cationic lipid. Electrostatic interactions can also be exploited to create nanoparticle-bound microbubbles. One example of this was described by Seo et al. who created positively charged monodisperse microbubbles through microfluidics and 
attached negatively charged silica coated nanoparticles [100]. This technique was shown to be effective for various sizes and shapes of nanoparticles.

Drugs can also be directly incorporated into the shell of the microbubble, although this provides a challenge in the inherently limited payload capacity. Drug-loaded polymer shelled microbubbles, whose thicker shells allow for higher drug loading, fragment into "nanoshards", which are less than 400nm [101-103]. These shards are small enough to extravasate from the vasculature of the tumor.

There are some definite advantages to linking the nanoparticle to the microbubbles. Along with being able to track the nanoparticle in circulation by ultrasound imaging of the microbubble carriers, attaching the nanoparticle ensures that they are present at the target site during insonation. Using ultrasound to rupture the microbubble at a desired location leads to targeted deposition of particles. As discussed earlier, linking the nanoparticle to the microbubble also allows for radiation force to be used to increase particle/drug concentration at the desired site. Lum et al. and Kheirolomoom et al. demonstrated higher delivery of nanoparticles in-vitro using radiation force in combination with microbubbleloaded nanoparticle constructs compared to without using radiation force [49, 93]. Linking nanoparticles to microbubbles is also advantageous because it prevents dilution of the nanoparticle solution when it enters the bloodstream [53]. Finally, microbubbles loaded with certain nanoparticles may serve as multi-modality contrast agents for platforms such as dual MRI-ultrasound and optical-ultrasound [104-106], although further discussion of these is beyond the scope of this review.

There are also some challenges related to associating the nanoparticle to the shell. When linking through a process such as biotin and avidin, multiple washing steps are necessary to remove free linking agent. This can be both time consuming and detrimental to the fragile bubble preparation, requiring a higher initial concentration of microbubbles. Furthermore, excess nanoparticles are typically required to maximize loading. Finally, attaching the nanoparticle to the microbubble may alter the in-vivo circulation time and biodistribution. This is discussed further in the last section of our review.

\section{Ultrasound Setup}

There are a variety of ultrasound systems in use to accomplish microbubble-aided nanoparticle delivery. Many researchers use single element transducers powered by arbitrary waveform generators and amplifiers, whereas others use commercial therapy systems or even clinical imaging systems (Table 1). In [107], Seip et al. describe ideal qualities of a therapy system, including the ability to both image and treat a desired location in order to monitor delivery and release of the agent. The system should be able to generate intensities and pulse sequences needed for microbubble delivery, deliver focused energy deep within tissue to target a specific area, treat in an acceptable amount time, be incorporated into current treatment workflow, and be easy to use and set up. Most therapeutic treatments involve ultrasound with a center frequency around $1 \mathrm{MHz}$, which is much lower than clinical imaging systems typically provide. Although some custom systems have been created, dual imaging and treatment often requires multiple transducers to be used in conjunction with one another [108]. Nanoparticle delivery has been performed with both focused and unfocused transducers, as well as at varying pressures - up to 7MPa (Table 1).

\section{Successful Nanoparticle Delivery Studies}

Some of the first nanoparticle delivery studies were performed in-vivo with fluorescent nano/microspheres (100- $500 \mathrm{~nm}$ ) delivered to rat skeletal muscle [81, 109]. In these studies, vessel rupture caused by microbubble breaking was observed, and the particles were 
delivered into the intersitium of the muscle. Extravasation points were observed where particles and red blood cells leaked out of the vasculature (Fig 1). Findings also illustrated the importance of allowing microbubbles to replenish in between ultrasound pulses and quick (10 s) injection of particles to increase deposition. Delivery of fluorescent nanospheres (30-120 nm) to cardiac muscle was later shown by Vancraeynest et. al [82].

Feasible in-vivo nanoparticle drug delivery with microbubbles and ultrasound was demonstrated with fibroblast growth factor-2 loaded PLGA nanoparticles [110]. Initial studies depicted 40 fold and 670 fold increases in nanoparticle delivery to the mouse adductor muscle when ultrasound or ultrasound and microbubbles were applied compared to nanoparticles alone. Subsequently, drug loaded nanoparticles were delivered into the ischemic hind limb of the mouse with the addition of ultrasound and microbubbles. Results of the studies showed an increase in total number of large and moderate diameter arterioles, as well as marked luminal expansion of pre-existing collateral arteries and transverse arterioles. Although the growth factor did not induce angiogenesis in gracilis muscles, arteriogenic remodeling was seen along with an increase in arteriole-line intersections (Fig 2).

Successful nanoparticle gene delivery was demonstrated in-vitro with plasmid DNA (pDNA), short interfering RNA (siRNA) and messenger RNA (mRNA), often involving a fluorescently tagged gene so that transfection can be easily quantified [55-57, 111, 112]. Encapsulating the genetic material within a liposome, creating a lipoplex, or siPlex, protects the genetic material and allows more to be delivered to the target site. Ultrasound mediated delivery with microbubbles was found to overcome the limitations of PEGylated liposomes. Although PEG increases circulation of the lipo/siPlexes, it hinders cellular uptake. When cells in an Opticell were exposed to ultrasound, liposomes loaded with up to $15 \mathrm{~mol} \%$ PEG had limited gene expression/inhibition with free liposomes, but exposure to loaded microbubbles and ultrasound led to statistically significant differences (Fig 3,4). These studies also demonstrated the direct entry of liposomes into the cytoplasm when ultrasound and microbubbles are present [56]. Uptake and expression was investigated further with mRNA lipoplexes loaded on to microbubbles [57]. Uptake was observed in 50\% of the cells when loaded microbubbles and ultrasound were applied, compared to $0 \%$ uptake with lipoplexes alone, and $24 \%$ of the cells illustrated successful transfection. These results support the hypothesis that not all of the contents are released from liposomes upon insonation.

Liposomal loaded microbubbles have also proven to be advantageous for drug delivery. As mentioned in an earlier section, Doxil, and other doxorubicin containing liposomes are commonly used in ultrasound and microbubble delivery studies. When doxorubicincontaining liposomes were bound to microbubbles and delivered to melanoma cells in an Opticell, significantly higher cytotoxicity was seen (Fig 5)[113]. Additional findings indicated that enhanced delivery was caused by both release of doxorubicin from liposomes and sonoporation caused by the microbubbles. The released free doxorubicin enters into the cell more efficiently than the liposome contained doxorubicin. Studies carried out with selfassembling liposome loaded microbubbles revealed a lower dose of doxorubicin could be used when the liposomes were bound compared to free liposomes [51].

Recently, enhanced in-vivo delivery of liposomal doxorubicin has also been observed. After several studies with lipid coated quantum dots delivered in mice, studies were carried out with Doxil and microbubbles with ultrasound exposure [114]. The concentration of Doxil in tumor tissue over time, the impact on tumor size on various treatments, and dose were investigated. Using focused ultrasound, more Doxil was delivered when microbubbles were administered, and colorectal adenocarcinoma tumor growth in mice was hindered (Fig 6). At 
24 hours after treatment, more drug was concentrated within the tumor compared to treatments of Doxil alone, however, the concentrations of both treatments were similar by 48 hours. It was also observed that smaller tumors responded better to treatment than larger tumors at $5 \mathrm{mg} / \mathrm{kg}$. Larger tumors required a higher treatment dose of $10 \mathrm{mg} / \mathrm{kg}$. Tumor histology revealed extravasation of fluorescent Doxil (Fig 7).

Delivery of doxorubicin-containing nanoshards has also been carried out in-vivo. Polymer microbubbles containing doxorubicin in the shell were destroyed within VX2 tumor bearing rabbits, which created nanoshards capable to extravasating into tumor tissues. Initial studies revealed significantly higher concentration of doxorubicin within the periphery of the tumor following ultrasound treatment compared to no insonation [102]. In later work, significant differences in tumor growth were also observed between mice treated with drug loaded microbubbles and ultrasound compared to free drug at 14 days (Fig 8) [115]. Paclitaxel loaded polymer microbubbles are also being developed which can hold up to 20 times as much drug as doxorubicin loaded microbubbles [101].

Nanoparticle drug delivery has also recently been applied to fields outside of chemotherapy [116]. Microbubbles loaded with rapamycin coated magnetic ion nanoparticles are being investigated as a treatment option for ischemic coronary heart disease. Using magnetic stents, the nanoparticle loaded microbubbles are targeted to the desired location, and then the drug is released when the microbubbles are ruptured using ultrasound. In-vitro studies have shown cell growth inhibition with rapamycin loaded nanoparticles, while testing of the magnetic stents confirms microbubble accumulation at the stent. Increasing the flow conditions lead to an increase in nanoparticle deposition.

\section{Considerations}

There are still many obstacles to overcome to translate microbubble mediated ultrasound delivery of nanoparticles into a clinical setting, but progress is being made as more in-vitro and in-vivo studies are being performed. Work remains to be done on understanding the mechanisms taking place in-vivo in order to ensure that safe delivery can be achieved. Bioeffects will need to be closely monitored as tissue damage has been seen in some studies [82]. It will also be important to understand the biodistribution and pharmacokinetics of the nanoparticles when delivered with microbubbles. As discussed in [52], liposome nanoparticles generally have long circulation times, but when bound to microbubbles the complex is limited to the 5-10 minute circulation time of the microbubble. Although the microbubble mediated delivery method will increase the nanoparticle concentration at the target site, accumulation in other organs is always a major factor to consider, as drug or gene accumulation in non-targeted organs/tissues could be detrimental. For example, unlike with liposomes, a high concentration of lipid from circulating microbubbles is taken up by the spleen. Nanoparticles bound to the microbubble may therefore also end up in the spleen.

Another area that is actively under investigation is the effect of ultrasound on the integrity of the nanoparticle, and how bound nanoparticles disassociate from microbubbles. There have been conflicting reports about how and if the nanoparticle is released from the shell. Lum et al. detected lipid labeled with DiI on the nanoparticles after breaking the microbubble [93]. However, other groups have found that the nanoparticle breaks free [49, 55, 112]. Ultrasound exposure has also been shown in some cases to cause release of the contents [52, 113], whereas in other studies the cargo remains intact within the liposome carriers [111, $112]$.

Loading optimization also needs to be addressed. Loading estimates of liposomes onto microbubbles have been between 600 and 10000 liposomes per microbubble, depending on the size of both the microbubble and the liposome [49, 51, 52]. This may be complicated 
further by the fact that lipids are not uniformly distributed through the shell layer of microbubble, resulting in heterogeneous loading of nanoparticles [93, 117]. Uniform loading is desirable in order to accurately quantify the amount of drug or gene on each bubble, and therefore delivered to the target site. Optimization of loading is challenging because it is frequently difficult to determine concentrations of nanoparticle solutions due to their small size. Although binding can be confirmed through methods such as flow cytometry, UV spectrometry, and microscopy, exact numbers of bound nanoparticles are difficult to obtain.

Further optimization of both ultrasound settings and delivery vehicle design are also needed. Because a variety of systems exist which deliver ultrasound energy, there is also a wide range of settings in use. Currently, comparisons between studies are hard to make because of the highly-variable acoustic parameters used from study to study. Aside from ultrasound systems and settings, different microbubble formulations and nanoparticles are used that influence the results of each study. Further refining of microbubble populations through size selection techniques may be a way to improve the effectiveness of delivery methods. Microbubble populations with high uniformity in size may allow optimal loading of particles onto the shell along with a better prediction of the microbubble response to ultrasound [119]. Additionally, further study of the tradeoffs between bound and free nanoparticle delivery are needed for each application.

Despite the challenges being faced in the field of nanoparticle delivery, many advances are being made with the use of ultrasound and microbubbles, and the approach is developing into a promising method to improve treatments in cancer and genetic disorders.

\section{Supplementary Material}

Refer to Web version on PubMed Central for supplementary material.

\section{Acknowledgments}

Research on acoustically mediated therapeutics in the Dayton lab has been financially supported by the NIH through R01 EB008733 and R21 EB011704, as well as pilot grants from the Carolina Center for Cancer Nanotechnology Excellence and the University Research Council. The authors appreciate the efforts of Paul Sheeran with editing.

\section{References}

1. Ferrara KW, Borden MA, Zhang H. Lipid-shelled vehicles: engineering for ultrasound molecular imaging and drug delivery. Acc Chem Res. 2009; 42:881-892. [PubMed: 19552457]

2. Lentacker I, De Smedt SC, Sanders NN. Drug loaded microbubble design for ultrasound triggered delivery. Soft Matter. 2009; 5:2161-2170.

3. Mayer CR, Geis NA, Katus HA, Bekeredjian R. Ultrasound targeted microbubble destruction for drug and gene delivery. Expert Opin Drug Deliv. 2008; 5:1121-1138. [PubMed: 18817517]

4. Tinkov S, Bekeredjian R, Winter G, Coester C. Microbubbles as ultrasound triggered drug carriers. J Pharm Sci. Jun.2009 98:1935-1961. [PubMed: 18979536]

5. Dayton PA, Rychak JJ. Molecular ultrasound imaging using microbubble contrast agents. Front Biosci. 2007; 12:5124-5142. [PubMed: 17569635]

6. Sirsi S, Borden M. Microbubble compositions, properties and biomedical applications. Bubble Sci Eng Technol. 2009; 1:3-17. [PubMed: 20574549]

7. Wei K, Jayaweera AR, Firoozan S, Linka A, Skyba DM, Kaul S. Quantification of myocardial blood flow with ultrasound-induced destruction of microbubbles administered as a constant venous infusion. Circulation. 1998; 97:473-483. [PubMed: 9490243]

8. Blomley MJK, Cooke JC, Unger EC, Monaghan MJ, Cosgrove DO. Microbubble contrast agents: a new era in ultrasound. BMJ. 2001; 322:1222-1225. [PubMed: 11358777] 
9. Feinstein SB, Cheirif J, Ten Cate FJ, Silverman PR, Heidenreich PA, Dick C, Desir RM, Armstrong WF, Quinones MA, Shah PM. Safety and efficacy of a new transpulmonary ultrasound contrast agent: initial multicenter clinical results. J Am Coll Cardiol. 1990; 16:316-324. [PubMed: 2197312]

10. Goldberg BB, Liu JB, Forsberg F. Ultrasound contrast agents: a review. Ultrasound Med Biol. 1994; 20:319-333. [PubMed: 8085289]

11. Stuart Foster F, Burns PN, Simpson DH, Wilson SR, Christopher DA, Goertz DE. Ultrasound for the visualization and quantification of tumor microcirculation. Cancer Metastasis Rev. 2000; 19:131-138. [PubMed: 11191052]

12. Chomas JE, Pollard RE, Sadlowski AR, Griffey SM, Wisner ER, Ferrara KW. Contrast-enhanced US of microcirculation of superficially implanted tumors in rats. Radiology. 2003; 229:439. [PubMed: 14526091]

13. Burns PN, Wilson SR, Simpson DH. Pulse inversion imaging of liver blood flow: improved method for characterizing focal masses with microbubble contrast. Invest Radiol. 2000; 35:58. [PubMed: 10639037]

14. Wei K, Le E, Bin JP, Coggins M, Thorpe J, Kaul S. Quantification of renal blood flow with contrast-enhanced ultrasound. J Am Coll Cardiol. 2001; 37:1135-1140. [PubMed: 11263620]

15. Leong-Poi H, Christiansen J, Klibanov AL, Kaul S, Lindner JR. Noninvasive assessment of angiogenesis by ultrasound and microbubbles targeted to av-integrins. Circulation. 2003; 107:455-460. [PubMed: 12551871]

16. Ellegala DB, Leong-Poi H, Carpenter JE, Klibanov AL, Kaul S, Shaffrey ME, Sklenar J, Lindner JR. Imaging tumor angiogenesis with contrast ultrasound and microbubbles targeted to av $\beta 3$. Circulation. 2003; 108:336-341. [PubMed: 12835208]

17. Lindner JR, Song J, Xu F, Klibanov AL, Singbartl K, Ley K, Kaul S. Noninvasive ultrasound imaging of inflammation using microbubbles targeted to activated leukocytes. Circulation. 2000; 102:2745-2750. [PubMed: 11094042]

18. Lindner JR. Contrast ultrasound molecular imaging of inflammation in cardiovascular disease. Cardiovasc Res. 2009; 84:182. [PubMed: 19783842]

19. Billard BE, Hynynen K, Roemer RB. Effects of physical parameters on high temperature ultrasound hyperthermia. Ultrasound Med Biol. 1990; 16:409-420. [PubMed: 2396329]

20. Husseini GA, Pitt WG. The use of ultrasound and micelles in cancer treatment. J Nanosci Nanotechnol. 2008; 8:2205-2215. [PubMed: 18572632]

21. Hill CR, Ter Haar GR. High intensity focused ultrasound--potential for cancer treatment. Br J Radiol. 1995; 68:1296. [PubMed: 8777589]

22. Kennedy JE, Ter Haar GR, Cranston D. High intensity focused ultrasound: surgery of the future? Br J Radiol. 2003; 76:590. [PubMed: 14500272]

23. Bailey MR, Khokhlova VA, Sapozhnikov OA, Kargl SG, Crum LA. Physical mechanisms of the therapeutic effect of ultrasound - (A review). Acoustical Physics. Jul-Aug;2003 49:369-388.

24. Dalecki D. Mechanical bioeffects of ultrasound. Annu Rev Biomed Eng. 2004; 6:229-248. [PubMed: 15255769]

25. Alexandrov AV, Molina CA, Grotta JC, Garami Z, Ford SR, Alvarez-Sabin J, Montaner J, Saqqur M, Demchuk AM, Moyé LA. Ultrasound-enhanced systemic thrombolysis for acute ischemic stroke. N Engl J Med. 2004; 351:2170-2178. [PubMed: 15548777]

26. Tsutsui JM, Grayburn PA, Xie F, Porter TR. Drug and gene delivery and enhancement of thrombolysis using ultrasound and microbubbles. Cardiol Clin. 2004; 22:299. [PubMed: 15158941]

27. Unger EC, Porter T, Culp W, Labell R, Matsunaga T, Zutshi R. Therapeutic applications of lipidcoated microbubbles. Adv Drug Del Rev. May 7.2004 56:1291-1314.

28. Ferrara K, Pollard R, Borden M. Ultrasound microbubble contrast agents: Fundamentals and application to gene and drug delivery. Annu Rev Biomed Eng. 2007; 9:415-447. [PubMed: 17651012]

29. Liu YY, Miyoshi H, Nakamura M. Encapsulated ultrasound microbubbles: Therapeutic application in drug/gene delivery. J Controlled Release. Aug.2006 114:89-99.

30. Ferrara KW. Driving delivery vehicles with ultrasound. Adv Drug Del Rev. 2008; 60:1097-1102. 
31. Bekeredjian R, Grayburn PA, Shohet RV. Use of ultrasound contrast agents for gene or drug delivery in cardiovascular medicine. J Am Coll Cardiol. Feb.2005 45:329-335. [PubMed: 15680708]

32. Pichon C, Kaddur K, Midoux P, Tranquart F, Bouakaz A. Recent advances in gene delivery with ultrasound and microbubbles. J Exp Nanosci. 2008; 3:17-40.

33. Pitt WG, Husseini GA, Staples BJ. Ultrasonic drug delivery-a general review. Expert Opin Drug Deliv. 2004; 1:37-56. [PubMed: 16296719]

34. Haley B, Frenkel E. Nanoparticles for drug delivery in cancer treatment. Urol Oncol. 2008; 26:5764. [PubMed: 18190833]

35. Kim BYS, Rutka JT, Chan WCW. Nanomedicine. N Engl J Med. 2010; 363:2434-2443. [PubMed: 21158659]

36. Ferrari M. Cancer nanotechnology: Opportunities and challenges. Nat Rev Cancer. Mar.2005 5:161-171. [PubMed: 15738981]

37. Jain RK, Stylianopoulos T. Delivering nanomedicine to solid tumors. Nat Rev Clin Oncol. Nov. 2010 7:653-664. [PubMed: 20838415]

38. Danhier F, Feron O, Préat V. To exploit the tumor microenvironment: Passive and active tumor targeting of nanocarriers for anti-cancer drug delivery. J Controlled Release. 2010; 148:135-146.

39. Jeong W, Napier ME, DeSimone JM. Challenging nature's monopoly on the creation of welldefined nanoparticles. Nanomedicine (Lond). 2010; 5:633-639. [PubMed: 20528457]

40. Shubik P. Vascularization of tumors- a review. J Cancer Res Clin Oncol. 1982; 103:211-226. [PubMed: 6181069]

41. Hobbs SK, Monsky WL, Yuan F, Roberts WG, Griffith L, Torchilin VP, Jain RK. Regulation of transport pathways in tumor vessels: Role of tumor type and microenvironment. Proc Natl Acad Sci U S A. Apr 14.1998 95:4607-4612. [PubMed: 9539785]

42. Vaupel P. Tumor microenvironmental physiology and its implications for radiation oncology. Semin Radiat Oncol. 2004; 14:198-206. [PubMed: 15254862]

43. Jain RK. Delivery of novel therapeutic agents in tumors: physiological barriers and strategies. J Natl Cancer Inst. 1989; 81:570-576. [PubMed: 2649688]

44. Maeda $H$. The enhanced permeability and retention (EPR) effect in tumor vasculature: The key role of tumor-selective macromolecular drug targeting. Adv Enzyme Regul. 2001; 41:189-207. [PubMed: 11384745]

45. Kruse DE, Lai CY, Stephens DN, Sutcliffe P, Paoli EE, Barnes SH, Ferrara KW. Spatial and temporal-controlled tissue heating on a modified clinical ultrasound scanner for generating mild hyperthermia in tumors. IEEE Trans Biomed Eng. 2010; 57:155-166. [PubMed: 20064754]

46. Shrestha A, Fong SW, Khoo BC, Kishen A. Delivery of antibacterial nanoparticles into dentinal tubules using high-intensity focused ultrasound. J Endod. 2009; 35:1028-1033. [PubMed: 19567328]

47. Ohl SW, Shrestha A, Khoo BC, Kishen A. Characterizing bubble dynamics created by highintensity focused ultrasound for the delivery of antibacterial nanoparticles into a dental hard tissue. Proc Inst Mech Eng H. 2010; 224:1285-1296. [PubMed: 21218691]

48. Lin CY, Liu TM, Chen CY, Huang YL, Huang WK, Sun CK, Chang FH, Lin WL. Quantitative and qualitative investigation into the impact of focused ultrasound with microbubbles on the triggered release of nanoparticles from vasculature in mouse tumors. J Controlled Release. 2010; 146:291-298.

49. Kheirolomoom A, Dayton PA, Lum AFH, Little E, Paoli EE, Zheng HR, Ferrara KW. Acoustically-active microbubbles conjugated to liposomes: Characterization of a proposed drug delivery vehicle. J Controlled Release. Apr.2007 118:275-284.

50. Unger EC, McCreery TP, Sweitzer RH. Ultrasound enhances gene expression of liposomal transfection. Invest Radiol. Dec.1997 32:723-727. [PubMed: 9406011]

51. Geers B, Lentacker I, Sanders NN, Demeester J, Meairs S, De Smedt SC. Self-assembled liposome-loaded microbubbles: The missing link for safe and efficient ultrasound triggered drugdelivery. J Controlled Release. 2011 
52. Klibanov AL, Shevchenko TI, Raju BI, Seip R, Chin CT. Ultrasound-triggered release of materials entrapped in microbubble-liposome constructs: A tool for targeted drug delivery. J Controlled Release. 2010; 148:13-17.

53. Burke CW, Hsiang YH, Alexander Et, Kilbanov AL, Price RJ. Covalently linking poly(lactic-coglycolic acid) nanoparticles to microbubbles before intravenous injection improves their ultrasound-targeted delivery to skeletal muscle. Small. 2010; 2011:201001934-201001934.

54. Du J, Shi QS, Sun Y, Liu PF, Zhu MJ, Du LF, Duan YR. Enhanced delivery of monomethoxypoly(ethylene glycol)-poly(lactic-co-glycolic acid)-poly l-lysine nanoparticles loading platelet-derived growth factor BB small interfering RNA by ultrasound and/or microbubbles to rat retinal pigment epithelium cells. J Gene Med. 2011; 13:312-323. [PubMed: 21674734]

55. Lentacker I, Vandenbroucke RE, Lucas B, Demeester J, De Smedt SC, Sanders NN. New strategies for nucleic acid delivery to conquer cellular and nuclear membranes. J Controlled Release. 2008; 132:279-288.

56. Lentacker I, Wang N, Vandenbroucke RE, Demeester J, De Smedt SC, Sander NN. Ultrasound exposure of lipoplex loaded microbubbles facilitates direct cytoplasmic entry of the lipoplexes. Mol Pharm. 2009; 6:457-467. [PubMed: 19718799]

57. De Temmerman ML, Dewitte H, Vandenbroucke RE, Lucas B, Libert C, Demeester J, De Smedt SC, Lentacker I, Rejman J. mRNA-Lipoplex loaded microbubble contrast agents for ultrasoundassisted transfection of dendritic cells. Biomaterials. 2011:1-8.

58. Hancock HA, Smith LH, Cuesta J, Durrani AK, Angstadt M, Palmeri ML, Kimmel E, Frenkel V. Investigations into pulsed high-intensity focused ultrasound-enhanced delivery: preliminary evidence for a novel mechanism. Ultrasound Med Biol. 2009; 35:1722-1736. [PubMed: 19616368]

59. van Wamel A, Kooiman K, Harteveld M, Emmer M, ten Cate FJ, Versluis M, de Jong N. Vibrating microbubbles poking individual cells: Drug transfer into cells via sonoporation. J Controlled Release. May.2006 112:149-155.

60. Meijering BDM, Juffermans LJM, van Wamel A, Henning RH, Zuhorn IS, Emmer M, Versteilen AMG, Paulus WJ, van Gilst WH, Kooiman K, de Jong N, Musters RJP, Deelman LE, Kamp O. Ultrasound and microbubble-targeted delivery of macromolecules is regulated by induction of endocytosis and pore formation. Circul Res. Mar.2009 104:679-U226.

61. Kooiman K, Emmer M, Foppen-Harteveld M, van Wamel A, de Jong N. Increasing the Endothelial Layer Permeability Through Ultrasound-Activated Microbubbles. IEEE Trans Biomed Eng. Jan. 2010 57:29-32. [PubMed: 19709954]

62. Wu JR, Ross JP, Chiu JF. Reparable sonoporation generated by microstreaming. J Acoust Soc Am. Mar.2002 111:1460-1464. [PubMed: 11931323]

63. Collis J, Manasseh R, Liovic P, Tho P, Ooi A, Petkovic-Duran K, Zhu YG. Cavitation microstreaming and stress fields created by microbubbles. Ultrasonics. Feb.2010 50:273-279. [PubMed: 19896683]

64. Postema M, Gilja OH. Ultrasound-directed drug delivery. Curr Pharm Biotechnol. 2007; 8:355361. [PubMed: 18289044]

65. Sboros V. Response of contrast agents to ultrasound. Adv Drug Del Rev. Jun.2008 60:1117-1136.

66. Postema M, Van Wamel A, Lancee CT, De Jong N. Ultrasound-induced encapsulated microbubble phenomena. Ultrasound Med Biol. Jun.2004 30:827-840. [PubMed: 15219962]

67. Yudina A, Lepetit-Coiffe M, Moonen CT. Evaluation of the temporal window for drug delivery following ultrasound-mediated membrane permeability enhancement. Mol Imag Biol. 13:239-49.

68. Karshafian R, Bevan PD, Williams R, Samac S, Burns PN. Sonoporation by ultrasound-activated microbubble contrast agents: effect of acoustic exposure parameters on cell membrane permeability and cell viability. Ultrasound Med Biol. 2009; 35:847-860. [PubMed: 19110370]

69. Deng CX, Sieling F, Pan H, Cui JM. Ultrasound-induced cell membrane porosity. Ultrasound Med Biol. Apr.2004 30:519-526. [PubMed: 15121254]

70. Guzman HR, Nguyen DX, Khan S, Prausnitz MR. Ultrasound-mediated disruption of cell membranes. I. Quantification of molecular uptake and cell viability. J Acoust Soc Am. Jul.2001 110:588-596. [PubMed: 11508983] 
71. Duvshani-Eshet M, Baruch L, Kesselman E, Shimoni E, Machluf M. Therapeutic ultrasoundmediated DNA to cell and nucleus: bioeffects revealed by confocal and atomic force microscopy. Gene Ther. 2005; 13:163-172. [PubMed: 16177822]

72. Miller DL, Dou CY, Song JM. DNA transfer and cell killing in epidermoid cells by diagnostic ultrasound activation of contrast agent gas bodies in vitro. Ultrasound Med Biol. Apr.2003 29:601-607. [PubMed: 12749930]

73. Fan Z, Kumon RE, Park J, Deng CX. Intracellular delivery and calcium transients generated in sonoporation facilitated by microbubbles. J Controlled Release. 2010; 142:31-39.

74. Yang F, Zhang M, He W, Chen P, Cai X, Yang L, Gu N, Wu J. Controlled release of Fe3O4 nanoparticles in encapsulated microbubbles to tumor cells via sonoporation and associated cellular bioeffects. Small vol. 2011; 7:902-910.

75. Juffermans LJM, van Dijk A, Jongenelen CAM, Drukarch B, Reijerkerk A, de Vries HE, Kamp O, Musters RJP. Ultrasound and microbubble-induced intra- and intercellular bioeffects in primary endothelial cells. Ultrasound Med Biol. 2009; 35:1917-1927. [PubMed: 19766381]

76. Sheikov N, McDannold N, Vykhodtseva N, Jolesz F, Hynynen K. Cellular mechanisms of the blood-brain barrier opening induced by ultrasound in presence of microbubbles. Ultrasound Med Biol. Jul.2004 30:979-989. [PubMed: 15313330]

77. Choi JJ, Pernot M, Brown TR, Small SA, Konofagou EE. Spatio-temporal analysis of molecular delivery through the blood-brain barrier using focused ultrasound. Phys Med Biol. Sep 21.2007 52:5509-5530. [PubMed: 17804879]

78. Choi JJ, Feshitan JA, Baseri B, Wang SG, Tung YS, Borden MA, Konofagou EE. Microbubblesize dependence of focused ultrasound-induced blood-brain barrier opening in mice in vivo. IEEE Trans Biomed Eng. Jan.2010 57:145-154. [PubMed: 19846365]

79. McDannold N, Vykhodtseva N, Hynynen K. Targeted disruption of the blood-brain barrier with focused ultrasound: association with cavitation activity. Phys Med Biol. Feb 21.2006 51:793-807. [PubMed: 16467579]

80. Bekeredjian R, Kroll RD, Fein E, Tinkov S, Coester C, Winter G, Katus HA, Kulaksiz H. Ultrasound targeted microbubble destruction increases capillary permeability in hepatomas. Ultrasound Med Biol. 2007; 33:1592-1598. [PubMed: 17618040]

81. Price RJ, Skyba DM, Kaul S, Skalak TC. Delivery of colloidal particles and red blood cells to tissue through microvessel ruptures created by targeted microbubble destruction with ultrasound. Circulation. 1998; 98:1264-1267. [PubMed: 9751673]

82. Vancraeynest D, Havaux X, Pouleur AC, Pasquet A, Gerber B, Beauloye C, Rafter P, Bertrand L, Vanoverschelde JLJ. Myocardial delivery of colloid nanoparticles using ultrasound-targeted microbubble destruction. Eur Heart J. 2006; 27:237-245. [PubMed: 16166101]

83. Stieger SM, Caskey CF, Adamson RH, Qin S, Curry FRE, Wisner ER, Ferrara KW. Enhancement of vascular permeability with low-frequency contrast-enhanced ultrasound in the chorioallantoic membrane model. Radiology. 2007; 243:112-121. [PubMed: 17392250]

84. Skyba DM, Price RJ, Linka AZ, Skalak TC, Kaul S. Direct in vivo visualization of intravascular destruction of microbubbles by ultrasound and its local effects on tissue. Circulation. Jul.1998 98:290-293. [PubMed: 9711932]

85. Caskey CF, Stieger SM, Qin S, Dayton PA, Ferrara KW. Direct observations of ultrasound microbubble contrast agent interaction with the microvessel wall. J Acoust Soc Am. Aug.2007 122:1191-1200. [PubMed: 17672665]

86. Chen H, Brayman AA, Bailey MR, Matula TJ. Blood vessel rupture by cavitation. Urol Res. 2010:1-6.

87. Chen H, Kreider W, Brayman AA, Bailey MR, Matula TJ. Blood vessel deformations on microsecond time scales by ultrasonic cavitation. Phys Rev Lett. 2011; 106:34301.

88. Chen H, Brayman AA, Kreider W, Bailey MR, Matula TJ. Observations of translation and jetting of ultrasound-activated microbubbles in mesenteric microvessels. Ultrasound Med Biol. 2011

89. Dayton PA, Morgan KE, Klibanov ALS, Brandenburger G, Nightingale KR, Ferrara KW. A preliminary evaluation of the effects of primary and secondary radiation forces on acoustic contrast agents. IEEE Trans Ultrason Ferroelectr Freq Control. Nov.1997 44:1264-1277. 
90. Dayton PA, Allen JS, Ferrara KW. The magnitude of radiation force on ultrasound contrast agents. J Acoust Soc Am. Nov.2002 112:2183-2192. [PubMed: 12430830]

91. Dayton P, Klibanov A, Brandenburger G, Ferrara K. Acoustic radiation force in vivo: a mechanism to assist targeting of microbubbles. Ultrasound Med Biol. 1999; 25:1195-1201. [PubMed: 10576262]

92. Rychak JJ, Klibanov AL, Hossack JA. Acoustic radiation force enhances targeted delivery of ultrasound contrast microbubbles: in vitro verification. IEEE Trans Ultrason Ferroelectr Freq Control. 2005; 52:421-433. [PubMed: 15857050]

93. Lum AFH, Borden MA, Dayton PA, Kruse DE, Simon SI, Ferrara KW. Ultrasound radiation force enables targeted deposition of model drug carriers loaded on microbubbles. J Controlled Release. 2006; 111:128-134.

94. Shortencarier MJ, Dayton PA, Bloch SH, Schumann PA, Matsunaga TO, Ferrara KW. A method for radiation-force localized drug delivery using gas-filled lipospheres. IEEE Trans Ultrason Ferroelectr Freq Control. 2004; 51:822-831. [PubMed: 15301001]

95. Bloch SH, Dayton PA, Ferrara KW. Targeted imaging using ultrasound contrast agents. Progress and opportunities for clinical research applications. IEEE Eng Med Biol Mag. 2004; 23:18-29. [PubMed: 15565796]

96. Dayton PA, Zhao S, Bloch SH, Schumann P, Penrose K, Matsunaga TO, Zutshi R, Doinikov A, Ferrara KW. Application of ultrasound to selectively localize nanodroplets for targeted imaging and therapy. Mol Imaging. 2006; 5:160. [PubMed: 16954031]

97. Lin CY, Huang YL, Li JR, Chang FH, Lin WL. Effects of focused ultrasound and microbubbles on the vascular permeability of nanoparticles delivered into mouse tumors. Ultrasound Med Biol. 2010; 36:1460-1469. [PubMed: 20800173]

98. Bayer EA, Wilchek M. The use of the avidin-biotin complex as a tool in molecular biology. Methods Biochem Anal. 1980; 26:1-45. [PubMed: 7392958]

99. Lozano MM, Starkel CD, Longo ML. Vesicles tethered to microbubbles by hybridized DNA oligonucleotides: flow cytometry analysis of this new drug delivery vehicle design. Langmuir. Jun 1.2010 26:8517-8524. [PubMed: 20229988]

100. Seo M, Gorelikov I, Williams R, Matsuura N. Microfluidic assembly of monodisperse, nanoparticle-incorporated perfluorocarbon microbubbles for medical imaging and therapy. Langmuir vol. 2010; 26:13855-13860.

101. Cochran MC, Eisenbrey J, Ouma RO, Soulen M, Wheatley MA. Doxorubicin and paclitaxel loaded microbubbles for ultrasound triggered drug delivery. Int J Pharm. Jul 29.2011 414:161170. [PubMed: 21609756]

102. Eisenbrey JR, Soulen MC, Wheatley MA. Delivery of encapsulated doxorubicin by ultrasoundmediated size reduction of drug-loaded polymer contrast agents. IEEE Trans Biomed Eng. Jan. 2010 57:24-28. [PubMed: 19709952]

103. Eisenbrey JR, Burstein OM, Kambhampati R, Forsberg F, Liu JB, Wheatley MA. Development and optimization of a doxorubicin loaded poly(lactic acid) contrast agent for ultrasound directed drug delivery. J Controlled Release. Apr 2.2010 143:38-44.

104. Liu Z, Lammers T, Ehling J, Fokong S, Bornemann J, Kiessling F, Gätjens J. Iron oxide nanoparticle-containing microbubble composites as contrast agents for MR and ultrasound dualmodality imaging. Biomaterials. 2011; 32:6155-6163. [PubMed: 21632103]

105. Park JI, Jagadeesan D, Williams R, Oakden W, Chung S, Stanisz GJ, Kumacheva E. Microbubbles loaded with nanoparticles: a route to multiple imaging modalities. ACS Nano. 2010; 4:6579-6586. [PubMed: 20968309]

106. Ke H, Xing Z, Zhao B, Wang J, Liu J, Guo C, Yue X, Liu S, Tang Z, Dai Z. Quantum-dotmodified microbubbles with bi-mode imaging capabilities. Nanotechnology. 2009; 20:425105425105. [PubMed: 19779227]

107. Seip R, Chin CT, Hall CS, Raju BI, Ghanem A, Tiemann K. Targeted ultrasound-mediated delivery of nanoparticles: on the development of a new HIFU-based therapy and imaging device. IEEE Trans Biomed Eng. 2010; 57:61-70. [PubMed: 19695986] 
108. Hu X, Zheng H, Kruse D, Sutcliffe P, Stephens D, Ferrara K. A sensitive TLRH targeted imaging technique for ultrasonic molecular imaging. IEEE Trans Ultrason Ferroelectr Freq Control. 2010; 57:305-316. [PubMed: 20178897]

109. Song J, Chappell JC, Qi M, VanGieson EJ, Kaul S, Price RJ. Influence of injection site, microvascular pressure and ultrasound variables on microbubble-mediated delivery of microspheres to muscle. J Am Coll Cardiol. 2002; 39:726-731. [PubMed: 11849875]

110. Chappell JC, Song J, Burke CW, Klibanov AL, Price RJ. Targeted delivery of nanoparticles bearing fibroblast growth factor-2 by ultrasonic microbubble destruction for therapeutic arteriogenesis. Small vol. 2008; 4:1769-1777.

111. Lentacker I, De Smedt SC, Demeester J, Van Marck V, Bracke M, Sanders NN. Lipoplex-loaded microbubbles for gene delivery: A trojan horse controlled by ultrasound. Adv Funct Mater. 2007; 17:1910-1916.

112. Vandenbroucke RE, Lentacker I, Demeester J, De Smedt SC, Sanders NN. Ultrasound assisted siRNA delivery using PEG-siPlex loaded microbubbles. J Controlled Release. 2008; 126:265273.

113. Lentacker I, Geers B, Demeester J, De Smedt SC, Sanders NN. Design and evaluation of doxorubicin-containing microbubbles for ultrasound-triggered doxorubicin delivery: cytotoxicity and mechanisms involved. Mol Ther. 2009; 18:101-108. [PubMed: 19623162]

114. Lin CY, Li JR, Tseng HC, Wu MF, Lin WL. Enhancement of focused ultrasound with microbubbles on the treatments of anticancer nanodrug in mouse tumors. Nanomedicine. 2011; $\mathrm{xx}: \mathrm{xxx}-\mathrm{xxx}$.

115. Cochran MC, Jr E, Mc S, Sm S, Ro O, Sb W, Ee F, Ma W. Disposition of ultrasound sensitive polymeric drug carrier in a rat hepatocellular carcinoma model. Acad Radiol. 2011; 18:13411348. [PubMed: 21971256]

116. Räthel T, Mannell H, Pircher J, Gleich B, Pohl U, Krötz F. Magnetic stents retain nanoparticlebound antirestenotic drugs transported by lipid microbubbles. Pharm Res. 2011

117. Borden MA, Martinez GV, Ricker J, Tsvetkova N, Longo M, Gillies RJ, Dayton PA, Ferrara KW. Lateral phase separation in lipid-coated microbubbles. Langmuir. 2006; 22:4291-4297. [PubMed: 16618177]

118. F S, Kaya M, Hettiarachchi H, Lee AP, Dayton PA. Acoustic responses of monodisperse lipidencapsulated microbubble contrast agents produced by flow focusing. Bubble Sci Eng Technol. 2010; 2:33-40. [PubMed: 21475641]

119. Grainger SJ, Serna JV, Sunny S, Zhou Y, Deng CX, El-Sayed MEH. Pulsed ultrasound enhances nanoparticle penetration into breast cancer spheroids. Mol Pharm. Nov-Dec;2010 7:2006-2019. [PubMed: 20957996]

120. Hettiarachchi K, Zhang S, Feingold S, Lee AP, Dayton PA. Controllable microfluidic synthesis of multiphase drug-carrying lipospheres for site-targeted therapy. Biotechnol Prog vol. 2009; 25:938-45. 

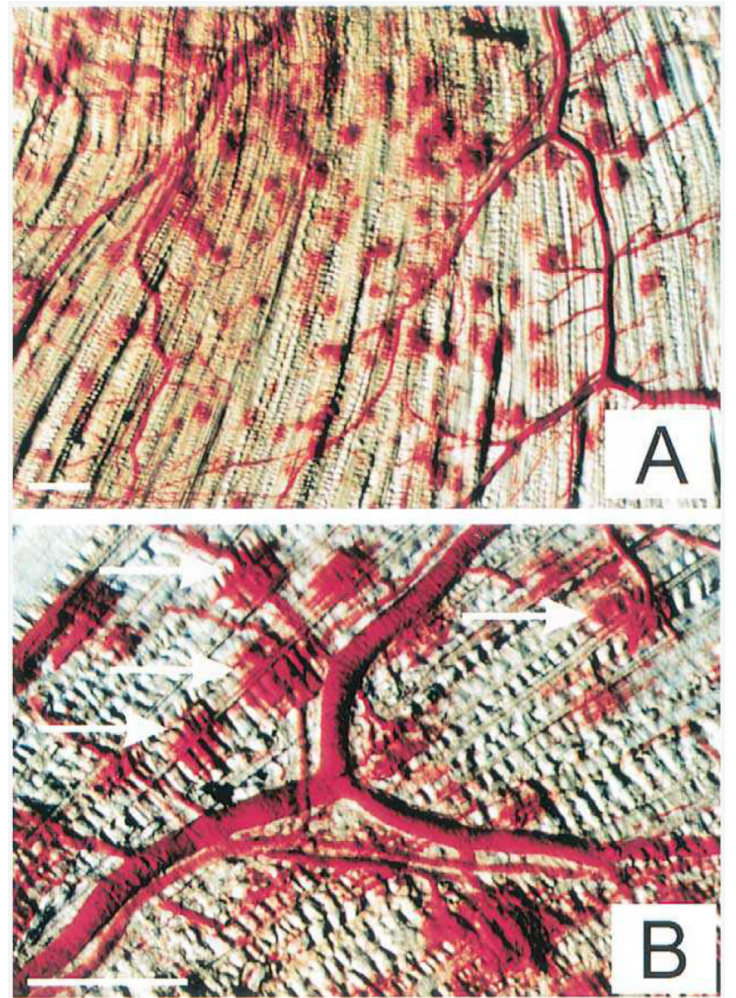

Figure 1.

Discrete extravasation points created by the application of $1 \mathrm{MHz}$ ultrasound to microbubbles flowing through skeletal muscle capillaries. Several extravasation points are highlighted with arrows in B.The specimen is from treatment group $\mathrm{C}$ [microbubble injection site: carotid artery, 40s injection, $5 \mathrm{~s}$ pulsing interval, 8 ultrasound pulses]. The bars indicate $1 \mathrm{~mm}$. Reprinted from Journal of the American College of Cardiology, 39/4, Song J, Chappell JC, Oi M, VanGieson EJ, Kaul S, Price RJ, "Influence of injection site, microvascular pressure and ultrasound variables on microbubble-mediated delivery of microspheres to muscle", 726-731, (2002), with permission from Elsevier. 

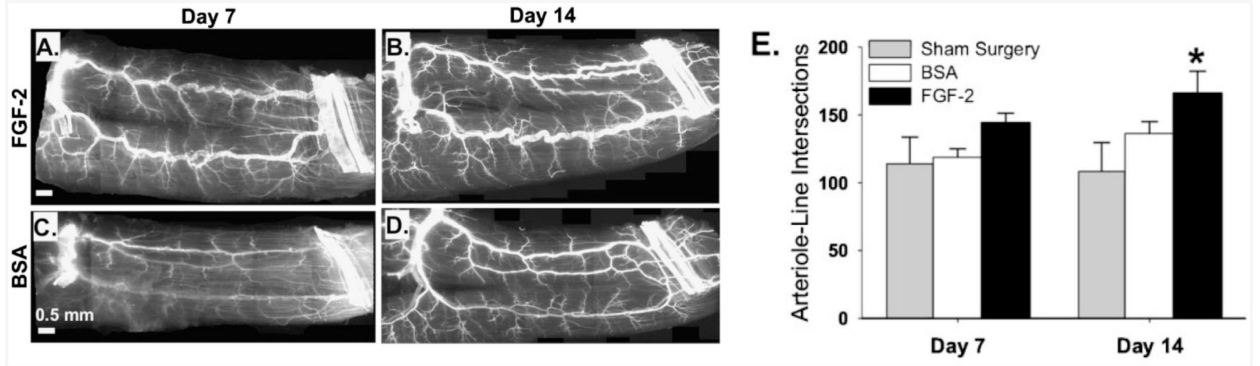

Figure 2.

The delivery of FGF-2bearing nanoparticles by ultrasonic microbubble destruction elicits arteriogenic remodeling in gracilis adductor muscle. A-D: Representative whole-mount images of fluorescently-labeled SM a-actin+ vessels in gracilis adductor muscles 7 and 14 days after FGF-2 (A and B) and BSA (C and D) treatment. Note the significant increase in arteriolar caliber and density in FGF-2-treated muscles. E: Bar graph of arteriole-line intersections at both time points for FGF-2, BSA, and sham surgery treatment. Values are means with standard errors. *indicates significantly different $(\mathrm{P}<0.05)$ than BSA and sham surgery at day 14. Reprinted from [110], with permission from John Wiley \& Sons Inc. 

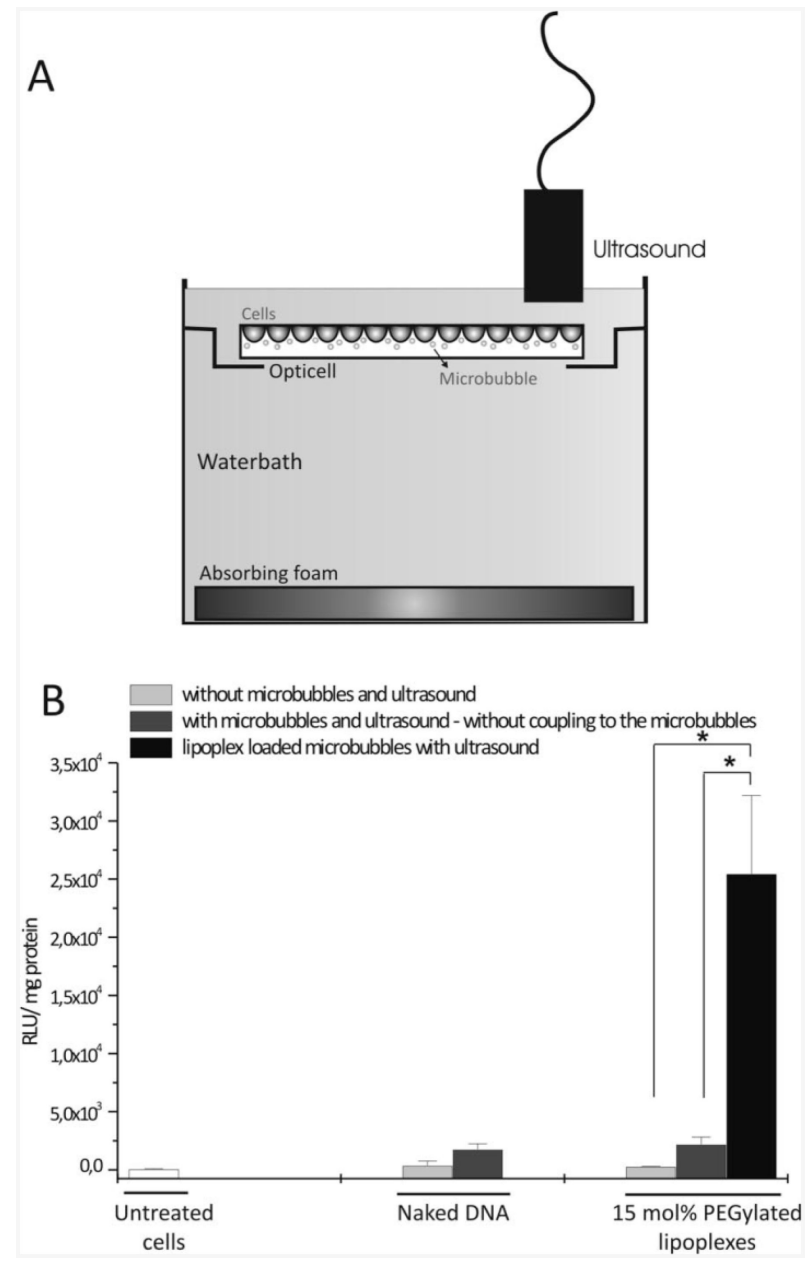

Figure 3.

Figure 2. (A) Schematic representation of the experimental setup. Cells were grown on one side of an Opticell unit. For ultrasound exposure, Opticell plates were turned upside down. In this way, microbubbles were able to rise against the cell layer. (B) The transfection efficiency of lipoplex loaded microbubbles in the presence of ultrasound (black bars) compared to the transfection efficiency of naked DNA and free $15 \mathrm{~mol} \%$ PEGylated lipoplexes in the absence (light gray bars) and presence of microbubbles and ultrasound (dark gray bars). The background luciferase signal in untreated cells is also shown (white bars). The transfection results, i.e., the extent of luciferase expression, are expressed as RLU (RLU: relative light units) per mg protein. ${ }^{*} \mathrm{p}<0.05$. Reprinted with permission from [56]. Copyright (2009) American Chemical Society. 


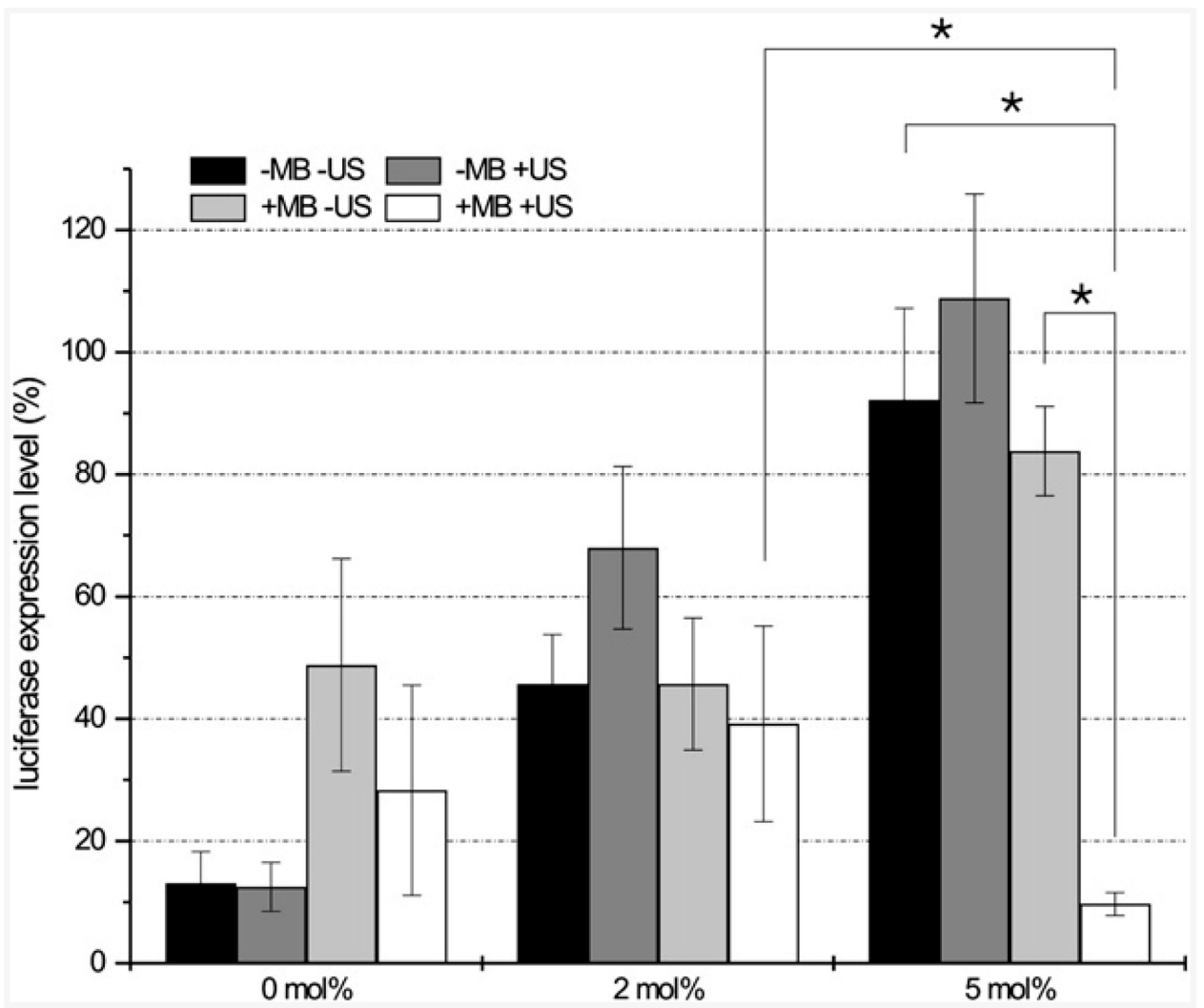

Figure 4.

Silencing efficiency of free siPlexes and PEG-siPlexes in the absence and presence of ultrasound, and PEG-siPlex loaded microbubbles in the presence of ultrasound. The PEGylation (DSPE-PEG2000-biotin) degree of the siPlexes is represented in the $\mathrm{x}$-axis. The black and the dark grey bars represent the gene silencing efficiency of free siPlexes in the absence and presence of ultrasound, respectively. The light grey and white bars represent the gene silencing of the siPlexes loaded on the microbubbles in the absence or presence of ultrasound. In all cases, the following ultrasound settings were used: $1 \mathrm{MHz}, 10 \% \mathrm{DC}, 2 \mathrm{~W} /$ $\mathrm{cm} 2,10 \mathrm{~s}$. The results are expressed as percentage of luciferase expression compared to mock siRNA transfected cells. The asterisks $(*)$ represent significant differences with $\mathrm{p}<0.05$. $(\mathrm{MB}=$ microbubble; US = ultrasound). Reprinted from Journal of Controlled Release, 126/3, Vanderbroucke RE, Lentaker I, Demeester J, De Smedt SC, Sanders NN, "Ultrasound assisted siRNA delivery using PEG-siPlex loaded microbubbles", 265-273, (2008), with permission from Elsevier. 


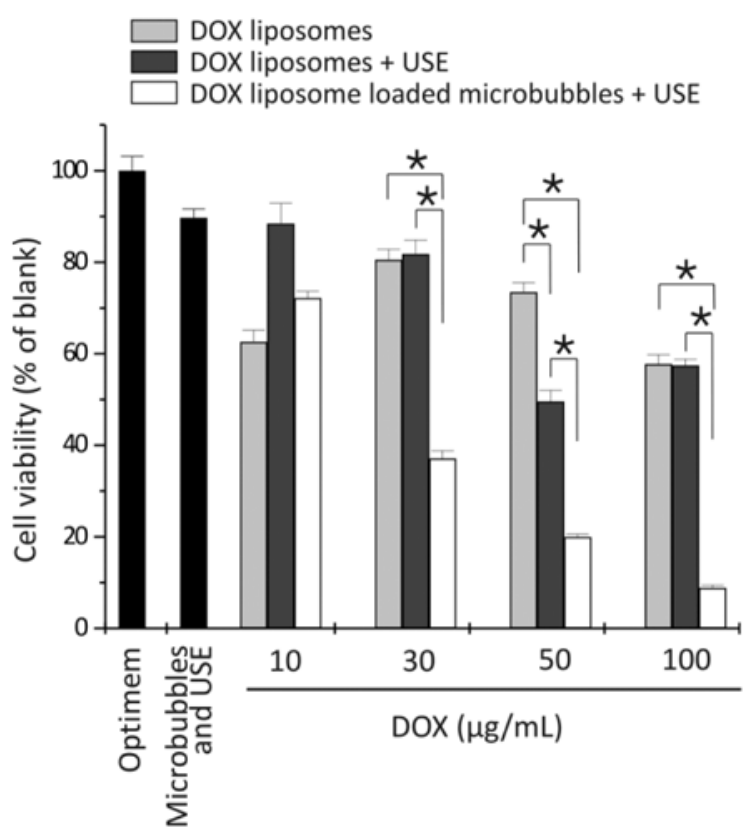

Figure 5.

Cell viability of the melanoma cells after treatment with DOX-liposomes without (light gray bars) and with ultrasound exposure (USE) (dark gray bars) and DOX-liposome-loaded microbubbles after ultrasound exposure (white bars) as a function of the DOX concentration in the OptiCell. For higher doxorubicin concentrations, more doxorubicin liposomes were used, whereas the microbubble concentration was always $10^{9}$ microbubbles per OptiCell unit. $* \mathrm{P}<0.05 . \mathrm{DOX}$, doxorubicin. Reprinted by permission from Macmillan Publishers Ltd: Molecular Therapy, [113], copyright (2009). 


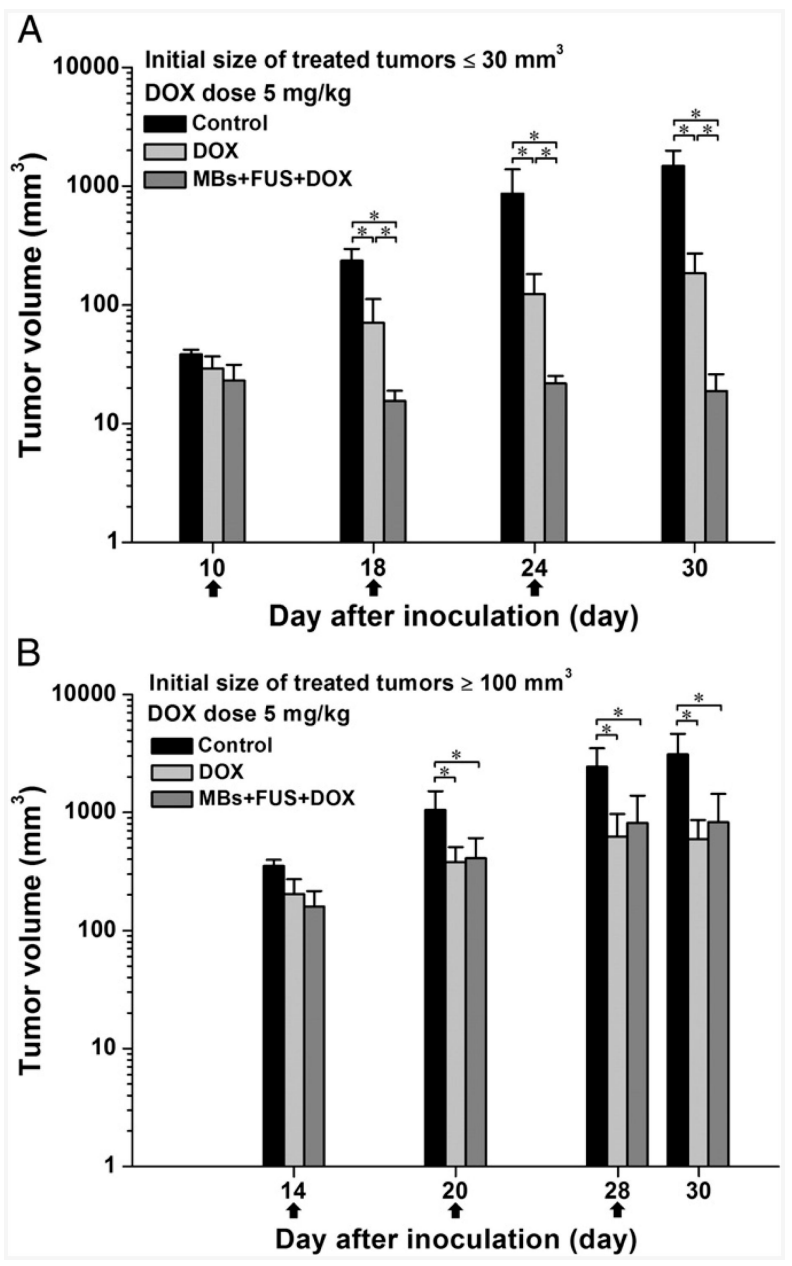

Figure 6.

Effect of initial size of treated tumors on the tumor growth response for the treatments with $5 \mathrm{mg} / \mathrm{kg}$ of DOX. The arrows indicate the schedule for treatments. (A) and (B) are the tumor growth responses for an initial size of treated tumors $\_30 \mathrm{~mm} 3$ and $\geq 100 \mathrm{~mm} 3$, respectively. $\mathrm{N}=5$ for each group, mean $\pm \mathrm{SD}$, and $* \mathrm{P}<0.05$ (Mann-Whitney $\mathrm{U}$ test). Reprinted from Nanomedicine: Nanotechnology Biology and Medicine, Lin C-Y, Li J-R, Tseng H-C, Wu M-F, Lin W-L, "Enhancement of focused ultrasound with microbubbles on the treatments of anticancer nanodrug in mouse tumors", 1-8, (2011), with permission from Elsevier. 


\section{(a)}

(a)

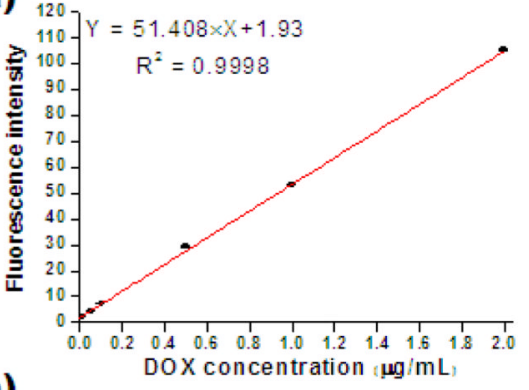

(b)

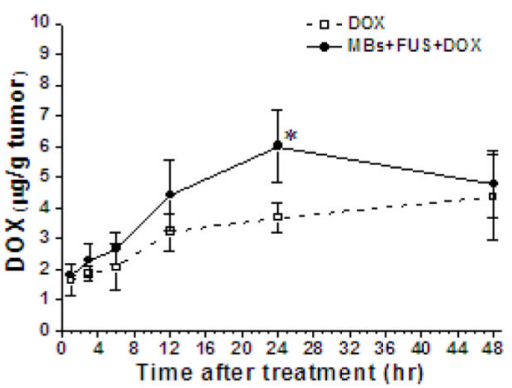

(c)
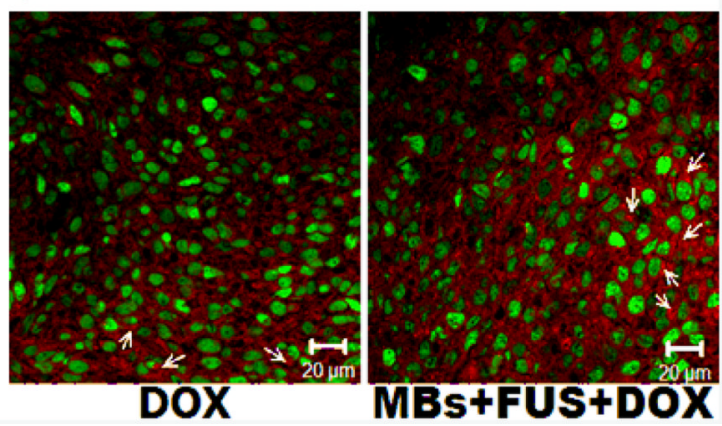

Figure 7.

Accumulation of DOX in the tumor tissues at 1, 3, 6, 12, 24 and $48 \mathrm{~h}$ after treatments. (A) shows the calibration curve illustrating the relationship between DOX concentration and fluorescent intensity at $582 \mathrm{~nm}$; (B) shows the DOX extracted from the tumor tissues treated with DOX or MBs+FUS+DOX $(5 \mathrm{mg} / \mathrm{kg}$ of DOX injected and $* \mathrm{P}<0.05$ at $24 \mathrm{~h}$ after treatments); (C) representative fluorescent images showing the DOX deposition (red, white arrow) related to CD31-stained blood vessels (green) at $24 \mathrm{~h}$ after treatments (magnification: 400x). $\mathrm{N}=3$ for each case. Reprinted from Nanomedicine: Nanotechnology Biology and Medicine, Lin C-Y, Li J-R, Tseng H-C, Wu M-F, Lin W-L, "Enhancement of focused ultrasound with microbubbles on the treatments of anticancer nanodrug in mouse tumors", $1-8,(2011)$, with permission from Elsevier. 


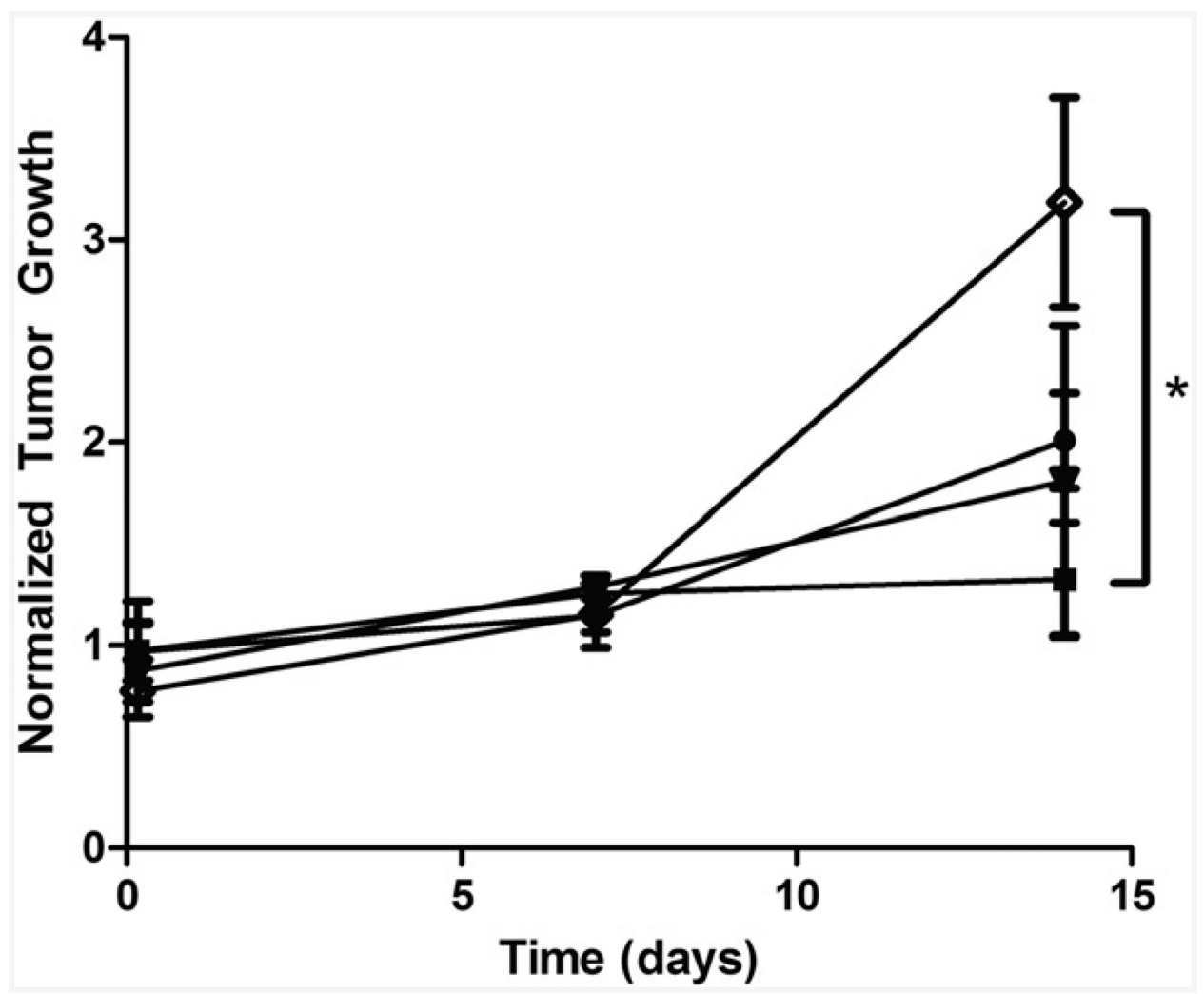

Figure 8.

Effect of vehicle on tumor growth in rats. Vehicles include; $12 \mathrm{mg} \mathrm{UCA} *, 12 \mathrm{mg}$ nanoparticles - a combination of $6 \mathrm{mg}$ nanoparticles and $6 \mathrm{mg} \mathrm{UCA} \bullet$, or free doxorubicin - All rats were insonated for 20 minutes after injection. Tumors treated with UCA did not show a significant increase in size over 14 days $(\mathrm{P}=.3)$ and had significantly less growth than rats treated with free doxorubicin after 14 days $(\mathrm{P}=.0390)$. Reprinted from Academic Radiology, 18/11, Cochran MC, et al., "Disposition of ultrasound sensitive polymeric drug carrier in a rat hepatocellular carcinoma model, 1341-1348,(2011), with permission from Elsevier. 


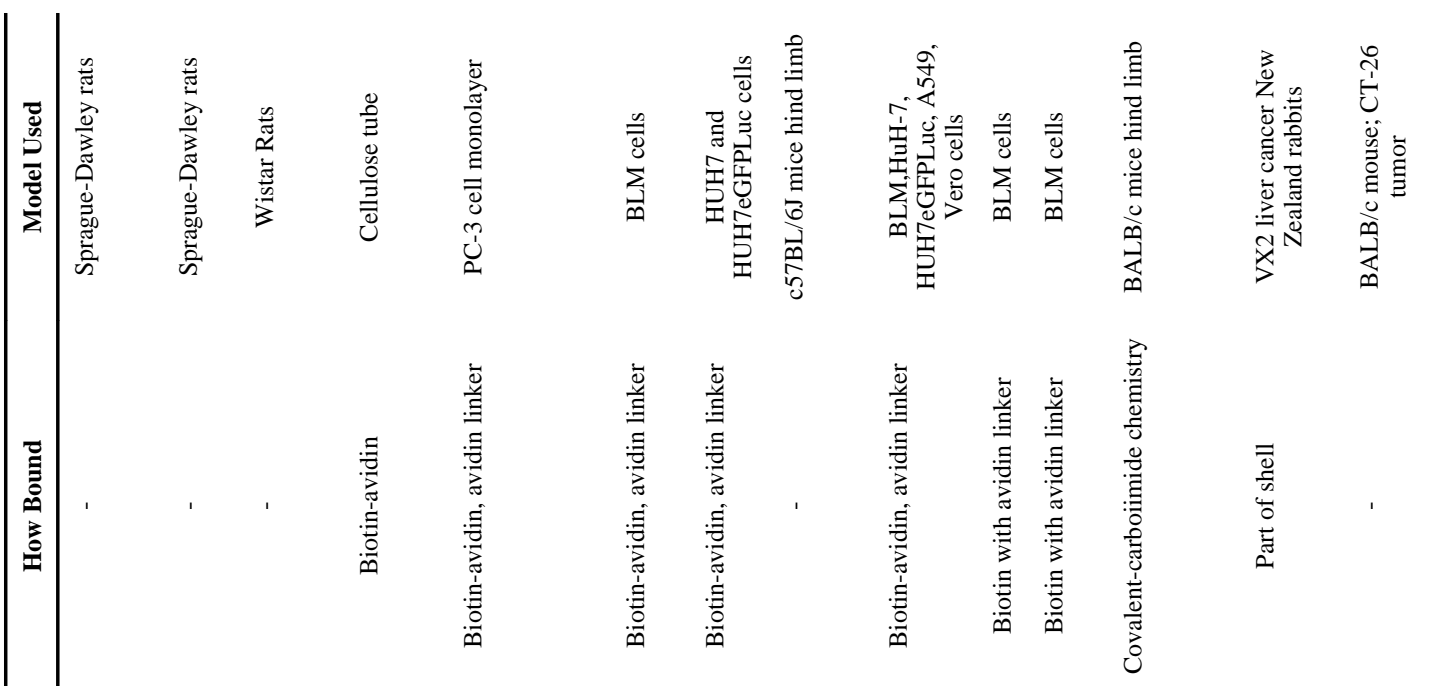

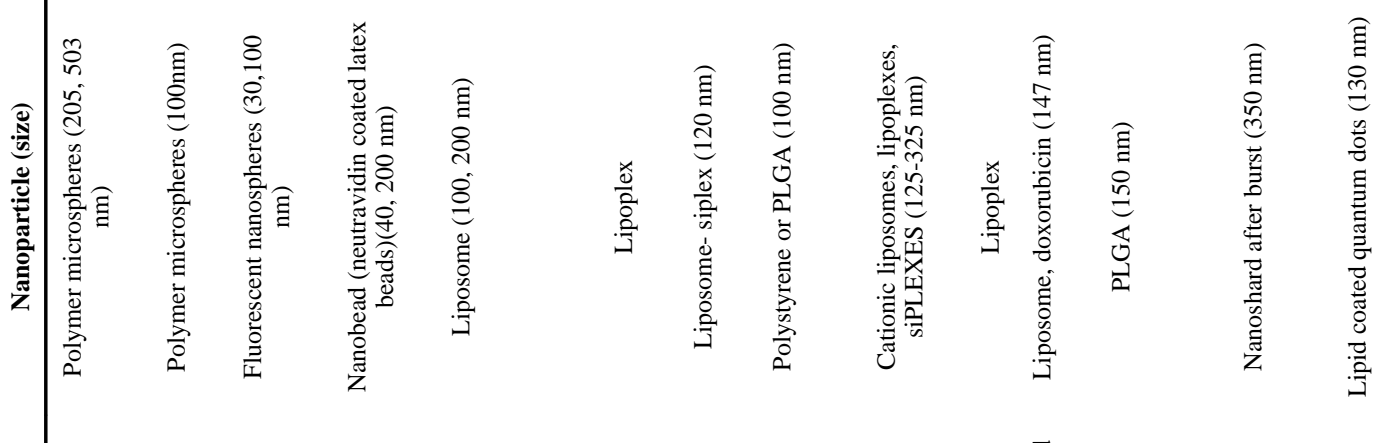

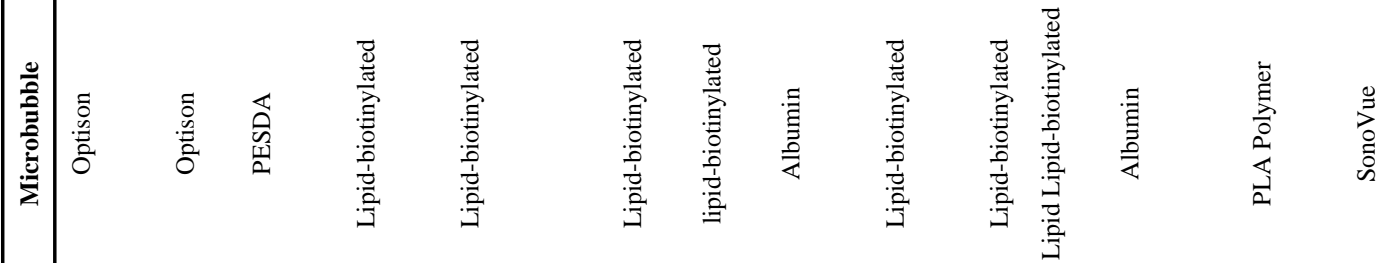


Mullin et al.

Page 24

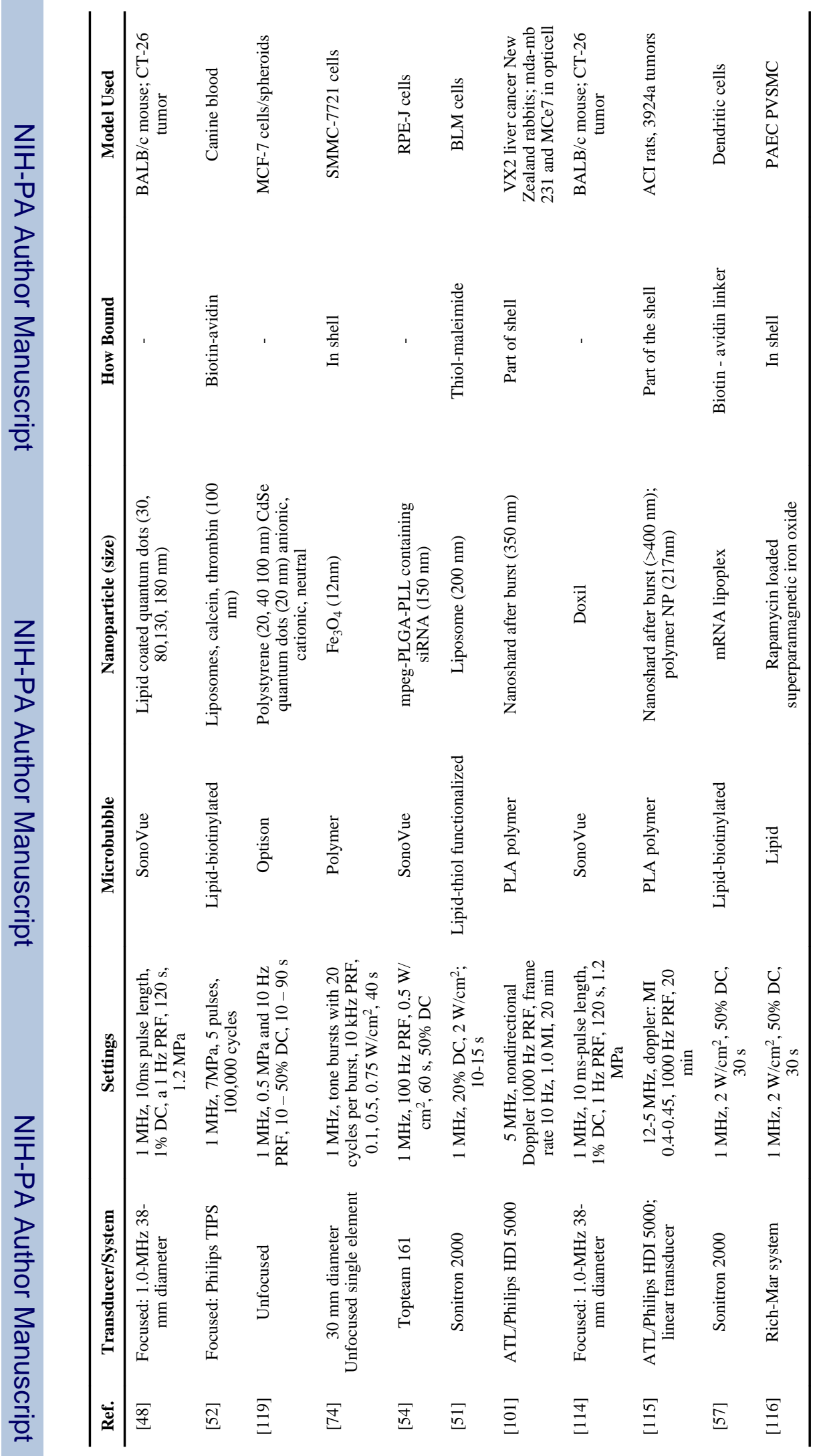

IEEE Trans UItrason Ferroelectr Freq Control. Author manuscript; available in PMC 2014 January 01. 